resulted also in a marked decrease in the incidence of "new thrombosis" diagnosed from the third day onwards: two legs thrombosed in the treated group but 10 in the untreated group. How can such brief treatment have a continuing protective effect between the third and the sixth days?

May I suggest that the thrombi diagnosed for the first time after the second day may in fact have existed since the operation but were too small originally to be detected with certainty by this method and that intermittent compression usually prevented the formation of these tiny thrombi also. I suspect that "thrombi" varying in size from a few platelet aggregates up to $1 \mathrm{~cm}$ in length ${ }^{1}$ are often formed, especially when conditions are favourable as during an operation. They are clinically silent and usually disappear without trace. These then represent a potentially dangerous nidus on which clinically evident thrombi can grow, again given appropriate conditions.

This raises the problem of whether to attempt to treat ever-smaller subclinical thrombi or to aim at preventing their growth.

It is also of interest that Dr. Roberts and Mr. Cotton think that thrombosis in malignancy may constitute a special case. We have studied 41 surgical patients before (as well as after) operation, and followed them up to see if they developed thrombosis. The patients preoperatively differed from controls in many platelet function tests and the presence of malignancy accounted for most but not all of these differences. ${ }^{2}-\mathrm{I}$ am, etc.,

J. R. O'BRIEN

Portsmouth and Isle of Wight Pathology Service,

Central Laboratory, Portsmouth

1 Havig, $\varnothing$., International Congress of Thrombosis and Haemostasis Abstract IV, Paper 239, Vienna

2 O'Brien, J. R., Tulevski, V. G., Etherington, M. Madgwick, T., Alkjaersig, N., and Fletcher, A. 7974, 83, 342 .

\section{Chronic Brucellosis}

SIR,-Many will conclude from the letter from Sir James Howie (16 March, p. 516) that the antibiotic of choioe in the treatment of chronic brucellosis is clomocycline. I have not used this preparation but there would seem little reason, on theoretical grounds and from a search of the literature, to prefer it to tetracycline $2 \mathrm{~g}$ daily, combined at first with intramuscular streptomycin. Could Sir James kindly say whether in his patient this regimen had been tried and had failed, and whether he considers that the duration of follow-up after treatment with clomocycline alone was long enough to ensure against the possibility of relapse?

Clomocyoline has been claimed to be effective in avoiding the colonic disturbances associated with prolonged antibiotic therapy ${ }^{1}$ but in my experience it is rarely necessary to discontinue tetracycline for this reason. To an impoverished exchequer, incidentally, the cost of treating with clomocycline for six weeks is $£ 13.18$ or more and with tetracycline for the same period $£ 4.09$ or less-in hospital very much less.-I am, etc.,

Pembroke County War Memorial Hospital,

EIRIAN WILLIAMS

1 Payne, D., Medicine (London). 1972, pt. 6, 499.
Circadian Rhythm of Cortisol Secretion in Elderly and Blind Subjects

SIR,-At the recent conference of the World Medical Association (3 November, p. 292), some applications of computers in medicine were discussed, such as automation of medical laboratories, rationalization of medical reporting, and analysis of biosignals.

Halberg et al. ${ }^{2}$ developed a technique to study biorhythm by computer (microscopic evaluation of data or Cosinor) We have used this technique to evaluate the data collected in an investigation of the circadian rhythm of human plasma cortisol concentrations in elderly normal subjects, in elderly patients with cerebrovascular hemiplegia, and in blind subjects. ${ }^{34}$

Forty elderly male volunteers, grouped as followis, were observed: (1) 18 normal subjects aged 62-88 (average 73.11 years; (2) 11 patients with cerebrovascular hemiplegia aged 62-83 (average 67.09) years; and (3) 11 patients with total chronic blindness for 412 years but with otherwise intact nervous system, aged 65-93 (average 74.27) years. All the patients had been in hospital for six months and had a 5-7 hour sleep rhythm (from 10 or 11 p.m. to 5 or 6 a.m.). Blood samples were drawn every three hours, starting at 6 a.m., for 24 hours or in some cases for 48 hours. The plasma cortisol was analysed by Mattingly's fluorimetric method. The data obtained were analysed by the Cosinor method in the chronobiology laboratory of the University of Minnesota by courtesy of Professor F. Halberg.

The accompanying figure shows that in the normal subjects and in the patients with hemiplegia the error ellipse does not overlap the origin of the circle, which is significant evidence of a rhythm $(P=0.001)$. In the blind subjects the error ellipse covers the origin of the circle, so that there is no statistically significant evidence of rhythmical variations $(P=0.150)$. There are three possible interpretations of this last finding:

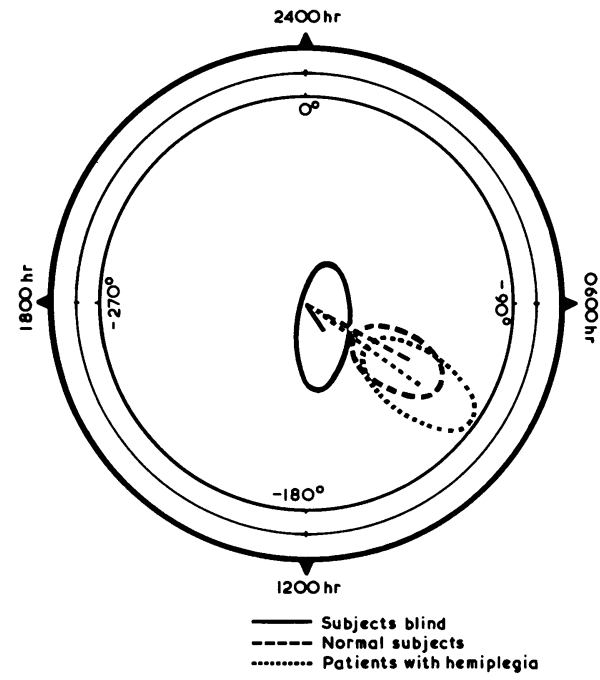

(1) loss of synchonizer light stimuli in blind people, particularly of the light/darkness alternating stimulus; (2) free-running rhythms $\mathrm{s}^{5}$ in blind people, with periods other than 24 hours and desynchronized in each subject; or (3) oircannual desynchronization in blind people whereby the different phase of circannual rhythm might overly the circadian rhythm variations.

Answers to these questions may be eventually provided by prolonged longitudinal studies and by repeated studies performed at yearly intervals in order to detect free rhythms and/or circannual variations. It seems certain, however, that lack of the light synchronizer modifies in some way the plasma cortisol biorhythm.-We are, etc.,

\section{B. D'Alessandro}

A. Bellastella V. Esposito

Institute of Medical Semeiotics,

C. F. Colucci

S. Maria della Pace Hospital,

N. Montalbetti

Magenta Hospital,

Magenta,

1 Halberg, F., Engeli, M., Hamburger, C., and Hillman, D., Acta Endocrinologica, 1965, Happl. 103, p. 54. Y L. Johnson, A., in Cellular Aspects of Biorhythms, ed. H. in The Cellular Aspects of Biorhythms, ed. 3 Bellastella, A., Colucci, C. F., D'Alessandro, B., Riforma Medica, 1972, 86, 18.

Bellastella, A., Colucci, C. F., D'Alessandro, B. Bollettino della Societa Italiana di Biologia Sperimentale, 1972, 48, 592 .

5 Orth, D. N., Island, D. P., Fournal of Clinical Endocrinology and Metabolism, 1969, 29,

\section{Reactions to Immunization}

SIR,-We wish to comment on some of the points raised in a recent edition of the "Nationwide" television programme, when Mr. Jack Ashley, M.P., and Professor George Dick discussed immunization. With particular reference to Professor Dick's statement that it is "important that babies are immunized by general practitioners because they are the people who know all about the babies and the families, whereas the clinic doctors may only see the baby for one time-that is, when he is being immunized," we would point out that immunization clinics are carried out in many child health centres all over the country by departmental medical officers, who until 31 March 1974 have constituted the medical staff of the local health authorities.

These doctors follow up the babies routinely at regular intervals for full developmental and physical examinations, apart from the examinations they carry out in conjunction with the immunization. They also ensure that they are acquainted with all the intercurrent illnesses and are helped to acquire this information by their close and constant association with health visitors. Full reports of such illnesses are routinely requested from general practitioners or hospital physicians.

Many of these doctors have a postgraduate qualification. Immunization is an important part of their work in the preventive sphere and all have to ensure that their knowledge of the hazards of immunization procedures remains up to date. On the whole they have more time than the general practitioner to discuss medical problems and explain reactions to parents. Some general practitioners, anyway, prefer not to do this work because they would be unable, for time reasons, to maintain a high level of immunization. Dr. E. P. James's letter (16 February, p. 287) does bring up exactly the 
same point, and we support his sentiments wholeheartedly.

We are not, of course, suggesting that general practitioners are unsuitable for this work. We merely point out that they are not alone in carrying it out or necssarily able to give better advice and care regarding the prevention of possible adverse reactions. In many instances they do undertake these sessions at child health centres.-We are, etc.,

JEAN DAVIES President

\section{S. J. MOCLATCHEY} Secretary

Maternal and Child Health Group, (formerly the Society of Medical Officers of Health) London N.6

\section{Misdiagnosis in Still's Disease}

SIR,-Your recent leading article (9 March, p. 406), which mentions most of the seronegative spondarthritides ${ }^{1}$ affecting children, omits reference to Reiter's disease. This, though uncommon in juveniles, is not a great ranity; Lockie and Hunder ${ }^{2}$ recently reviewed 21 adequately documented cases and the literature makes brief mention of a number of others. With most of the cases reviewed the onset was with diarrhoea and the established disease followed the pattern usually seen in adults, including the occasional case of monarticular involvement. . $^{3-5}$

We have recently seen three cases ${ }^{6}$ in boys aged 13, 14, and 15 years respectively. One of these was a post-dysenteric type and one presented with a monarticular arthritis. The 14-year-old developed the disease after sexual intercourse and already several recurrences have led to the development of a chronic erosive arthritis affecting the metararsophalangeal joints of the feet. Jonathan Hutchinson ${ }^{7}$ noted the infrequency of "post dysenteric rheumatism" in Britain, and it is clear that increasing promiscuity in young people has not led to an upsurge of juvenile cases of Reiter's disease from sexually acquired infection. Nonetheless, we wish to make the point that among children with arthritis there will be the very oocasional case of this disorder and misdiagnosis is quite likely if deliberate search for the often transient and inconspicuous ocular, mucosal, and genital signs is omitted in the early days of the first attack.-We are, etc.,

J. M. I. IVESON J. A. H. HANCOCK

Rheumatism Research Unit,

University of Leeds

1 Moll, J. M. H., and Wright, V., Seminars in Arrhritis and Rheumatism, 1973, 3, 55

Lorkie, G. N., and Hunder, G. G., Arthritis and Rheumatism, 1971, 14, 767.

Florman, A. L., and Goldstein, H. M., fournal of Pediatrics, 1948, 33, 172.

Jacobs, A. G., British Medical fournal, 1961, 2 , 5 Davies, N. E., Haverty, J. R.. and Bmtwright, M., Southern Medical fournal. 19k9, 62.1011.
6 Iveron, J. M. I., Nanda, B. S., Hancock,
J. A. H., Pownall, P. J., and Wright, V. In

7 Hutchinaton, J., Medical Press and Circular, 1880 (N.S.), 30, 2.

\section{Alcoholism and its Identification}

SrR,-On behalf of the Medical Council on Alcoholism I should like to comment on your leading article on this subject (20
April, p. 132). Much as we welcome the publicity you give to the grave problem of alcoholism and in acoord with you as we are that much remains to be done, there is little doubt that our members, among whom are most of the leading authorities on alooholism in this country, will feel that certainly in your last paragraph you do less than justice to the contributions of this council. We feel it is important and pertinent that the following facts should be known, not least to justify the benevolence of our financial supporters, among whom is the Department of Health and Social Security.

Letters and information on alcoholism, with an invitation to use our services, have been distributed to general practitioners throughout the Greater London area and in Lancashire and Yorkshire and are shortly to be distributed in the north-east. A film, "Alcoholism-a G.P.'s Problem?", has been made and widely shown in various parts of the country followed by discussion groups chaired or introduced by a member of the M.C.A. From all reports which come back to us these appear to have been successful and helpful ventures. Likewise two films on alcohol have been produced for teenagers and shown in schools and youth clubs. Good reports on these have been received. A film on treatment is being prepared under the overall direction of Dr. M. M. Glatt and parts of this film will be devoted to the treatment centres in London, Manchester, Edinburgh, and Cardiff. The Fournal of Alcoholism, which the M.C.A. produces quarterly, is distributed free to over 20,000 doctors in the United Kingdom and also has an overseas subscription. Eight thousand handbooks on alcoholism written specifically for health visitors have been distributed recently and a distribution of 25,000 handbooks written in conjunction with the Institute of Nursing will be sent out shortly.

As regards research, a comprehensive cross-cultural sociological survey into the drinking patterns of the young in Ireland and England has been sponsored by the M.C.A. for the past $2 \frac{1}{2}$ years, and in the opinion of our research committee will, on completion, make a valuable contribution to our understanding of the recent trend towards increased drinking among the young. We are also supporting research into discriminative aversive oontrol for alcoholics, prevalenoe of alcoholism, and management of alcoholism in general practice.

You rightly say that education within the profession is needed. We fully agree with this and in this sphere the M.C.A. has either organized or taken part in 36 seminars or discussion groups in various parts of England and Scotland during the past two years. A handbook on the facilities for the treatment of alcoholism has been distributed free to the majority of doctors throughout Great Britain and Northern Ireland. An international medical conference was organized at the Royal College of Physicians for five days in September 1973. It was attended by delegates from 18 countries and was favourably reported. The entire proceedings of this conference are about to be published. A one-day symposium for general practitioners was organized in conjunction with the Royal College of General Practitioners and one was also arranged for registrars in the London area and for medical officers of health. Notes on Alcohol and Alcoholism, published by the M.C.A., has been in much demand and has already gone into a second edition. Under consideration at present is a scheme for additional instruction in the subject of alcoholism for medical students. We have a comprehensive library and are subscribers to Medlars and the Classified Abstract Archive of the Alcohol Literature. This service is used by medical and paramedical staff and students from various disciplines.

As you indicate, the overall picture does not give grounds for complacency but we do feel that more is going on behind the scenes than your article would indicateand I repeat, it is to your last paragraph that we refer. Over the past five years few experts would deny a much greater awareness of alcoholism as a community health problem and we in the M.C.A. are very aware of this in the medical profession itself. It is vital that the many bodies concerned, both medical and paramedical, should work in close co-operation and should be aware of what is in fact being done, however slight the contributions might be in this vast and probably increasing problem

The President of our Council, Lord Porritt, and the Chairman, Sir Thomas Holmes Sellors, both agree with the purpose and the content of this letter.-I am, etc.,

Dick CaldWell Executive Director,
Medical Council on Alcoholism

London $\mathbf{W} .1$

\section{Training for General Practice}

SIR,-It is time that steps were taken to curb the almost hysterical obsession with vocational training which is affecting those powers which control the destinies of general practice. No one will deny that some sort of preparation is required by the new entrant, but we will shortly be in the position that the young doctor, having completed his spell in hospital and wishing to enter general practice, will be required to repeat the clinical years of the medical course that he took while a student-quite a ridiculous situation

When the trainee assistant scheme was started it was, of course, open to abuse, the trainee in some cases being used as subsidized extra help, but eventually responsibility for arranging suitable training courses fell upon the newly formed College of General Practitioners and, quite rightly, some form of control was exerted on both trainer and trainee, so that the imporfections of the scheme were gradually eliminated. Regrettably, however, the college has lost sight of the fact that the art of general practice can be acauired only by experience and cannot be taupht in the university or by sorving as a clinical assistant in a variety of hospital depar'ments. The college also has the rather ouaint notion that the granting of a diploma will turn an indiffer $n^{+}$G.P. into a good one and a rood C.P. in ${ }^{+} 0$ a groat one, forgetting that academic knowl-doe does not guarantee a good practitioner. There is no substirute for the apprenticeship system, so that all that is reauired is a year as a trainee working under supervision, probably on a quarerly basis with four different practices in that year. The college has its uses since 